light without heat for stimulating plant growth; and, of course, numerous examples of more ordinary instruments in new and improved designs.

The Research and Experimental Section provides always a fascinating display of the research physicists' work before it reaches the commercial production stage. Thirty-one of the research laboratories attached to Government departments, research associations, universities and manufacturing firms exhibited. Many of the devices shown had been developed for testing the properties and behaviour of a wide variety of materials under the differing conditions met with in practice, whilst several others were concerned with applications of cathode ray tubes and electron cameras to all manner of problems. One exhibit was staged to demonstrate the possibilities of ordering a number of different materials to match a given colour by quoting a standard name, number or code word, and another was designed for the routine measurement of the colour values of fabric and similar surfaces viewed by diffusely reflected light. Developments in the method of controlling the speed of small electric and mechanical motions by means of light tuning forks formed the subject of another exhibit. Others were, a galvano. meter which is said to be immune from mechanical disturbance of the zero, despite violent pitching and. rolling of the type met with in marine work, and a high speed motion picture timing system and camera which is said to take as many as 2,500 pictures a second.

Radio and telephony formed the subject of several important exhibits in the Research Section, and among these mention may be made of a standard receiver for the measurement of radio interference, a map of England and southern Scotland showing the electrical resistivity of the earth, and an 'artificial mouth' for testing telephones.

The growing use of discharge tubes for illumination purposes has led to the development of various devices for studying their behaviour, and some of these were exhibited. Another illumination device shown was a gas burner for producing an intermittent flame or light.

On each evening of the exhibition a discourse was delivered. The first was entitled "The Architecture of Molecules" in which Dr. B. Wheeler Robinson gave an account of recent $X$-ray investigations of molecular structure made at the Davy-Faraday Laboratory and elsewhere; the second was delivered by Dr. C. V. Drysdale on "The Problem of Ether Drift", a subject which readers of NATURE will know he has recently taken up with characteristic zeal; and on the third day, when the public is admitted to the Exhibition, the Astronomer Royal spoke on "Giant Telescopes".

The attendance at this year's Exhibition is not yet known, but in the past two years it has wanted but a few hundreds to be ten thousand. The Society is justly proud of the record of service it has rendered for so long to all those concerned with instruments, to the instrument industry in Great Britain, and to the public.

Herbert R. Lang.

\title{
Biochemistry of Marine Phytoplankton
}

A SERIES of papers on "Observations on the A Fatty Constituents of Marine Plankton" (J.Exp. Biol., 11, 173-197, 198-202, 203-209 ; 1934) sheds considerable light on the content of fat and vitamins $A$ and $D$ in plankton, on which all marine animal life is dependent directly or indirectly for existence.

In Part 1, on the "Biology of the Plankton" by E. R. Gunther, in order to convey a more precise idea of the relative importance of each species, an attempt is made to translate by means of suitable measurements the figures representing the numbers of a species present in a given quantity of plankton into figures representing the volume occupied by that species. The oil content of May phytoplankton from near the Isle of Man was about 6.9 per cent on the dry weight, and it is suggested that the oil content may vary with the species and fluctuate during the life-history. The oil content of July zooplankton varied between 15 and $19 \cdot 3$ per cent. In plankton giving a high oil yield, Calanus finmarchicus was very prominent.

In Part 2, on the "General Character of the Plankton Oils", G. Collin, J. C. Drummond, T. P. Hilditch and E. R. Gunther show that the fatty acid fraction of the zooplankton oils resembled that from fish liver oils. In the non-saponifiable fraction they demonstrated the presence of cholesterol, cetyl and eicoseneyl alcohols, a hydrocarbon suggestive of squalene and possibly batyl alcohol.

In Part 3, on "The Vitamin A and D Content of Oils derived from Plankton", J. C. Drummond and E. R. Gunther describe the results of an examination of the oils by feeding tests, with antimony trichloride and spectroscopically. They show that the phytoplankton oil is more potent than the zooplankton oil in its growth-promoting action, and this is correlated with a greater richness in lipochrome pigments related to carotene. Vitamin $\mathbf{A}$ as such is apparently absent from both phytoplankton and zooplankton. In testing for vitamin $\mathrm{D}$, the degree of healing was determined both by histological (line test) and by X-ray examinations. In daily doses of $50 \mathrm{mgm}$., phytoplankton oil showed no antirachitic activity but zooplankton showed slight activity. It is suggested that the small amount of vitamin D present in the animals results from their irradiation while in surface waters rather than from a prolonged diet of phytoplankton.

\section{Building in Earthquake Countries}

$\mathrm{W}^{\mathrm{s}}$ have received from Dr. C. E. Adams, Dominion astronomer and seismologist in New Zealand, several papers by Mr. R. W. de Montalk. In these, the author, who is an architect, describes a foundation, called the 'Salvus' foundation, that he has devised in order to lessen the effects of destructive earthquakes. It consists of a platform fixed to the ground. This is made of reinforced concrete, the under side of which may be strengthened, if necessary. Round the edge of the platform rises a rim of the same material, which contains a layer of clean fine shingle, 4-11 in. in depth according to the weight 
of the building. On this rests a slab, also of reinforced concrete, the foundation proper of the building, a space of about $4 \mathrm{in}$. being left between the walls and the inner edge of the rim.

When an earthquake occurs, the platform and shingle move with the earth under the building, which, not being fixed to the ground, tends to remain still. It is claimed that the 'Salvus' foundation not only saves the building from damage or destruction, but also lessens the risk of fire during an earthquake and also the effects of wind pressure on the building, while the shingle itself provides an excellent dampcourse. The additional cost ranges from $1 \frac{1}{4}$ per cent for large city buildings to 6 per cent for dwelling houses.

It may be recalled that, fifty years ago, Prof. Milne experimented with a similar foundation in Japan, and that, still earlier, lamp tables resting on spheres had been used in Japanese lighthouses by Messrs. Stevenson, the well-known lighthouse engineers ${ }^{1}$. Milne's building, $20 \mathrm{ft}$. $\times 14 \mathrm{ft}$., was made of wood and rested on four iron balls, 10 in. in dia meter. These lay on saucer-shaped iron plates fixed on the heads of piles, and similar plates attached below the building rested on the balls. From the records of seismographs placed inside, it was seen that, with an earthquake, there was a slow motion of the building to and fro, but that all the sudden motion or shock was destroyed. Afterwards, in order to increase the rolling friction, Milne lessened the size of the balls until each pier of the building rested on a handful of $\frac{1}{4}$-in. cast-iron shot. The house then stood firmly during storms of wind and, with the earthquake of February 12, 1884, it remained practically unmoved ${ }^{2}$.

C. D.

1 Nature, 32, 213, July 2; 222, July 9; 316, Aug. 6 ; 573, Oct. 15 ; 625, Oct. 29 ; 1885. 33, 7, Nov. 5 ; 435, March 11 ; 534, Apri $8 ; 1886$. 88,$15 ; 1885$.

\section{University and Educational Intelligence}

Cambridgr.-The Clerk Maxwell scholarship for original research in experimental physies and especially in electricity, magnetism and heat has been awarded to H. Carmichael, research student of St. John's College. The value of the scholarship is $£ 210$ a year for three years.

The Royal Technical College, Glasgow, after four years of decreasing student enrolments, is able to report for the past year an increase, from 878 to 910 , in the number of its day students, and although there was a small further decrease in the number of evening students (to 2,485 ) the aggregate number of hours of attendance shows an increase, and it is hoped that the downward trend since 1929 has at last been arrested. There was a marked increase in the volume of advanced work. Some indication of the exceptional range and standard of the evening classes is given by the fact that 95 graduates of the Universities of Glasgow, Edinburgh, Aberdeen, St. Andrews, Cambridge, London, Leeds, Sheffield, Belfast, Allahabad, Calcutta, Dacca, Madras, Rangoon and Kyoto were enrolled. The Research Journal inaugurated by the College ten years ago has published, in all, 167 original contributions by the staff and senior students, chiefly in the fields of chemistry (48), mechanical engineering (41), natural philosophy (25), metallurgy (16), bacteriology (14) and electrical engineering (11).

\section{Science News a Century Ago}

\section{Airy receives the Lalande Medal}

The Lalande Medal of the Paris Academy of Sciences, founded in 1802 by the famous French astronomer Jerôme de Lalande (1732-1807), was for some time the blue-riband of the astronomical world. In his "Autobiography", Airy recorded that in November 1834 "the Lalande Medal was awarded to me by the French Institut, and Mr. Pentland conveyed it to me in December". The following year he recorded, "On Jan. 9th 1835 I was elected correspondent of the French Academy ; and on Jan. 26th Mr. Pentland sent me $£ 12$ 6s., the balance of the proceeds of the Lalande Medal Fund".

\section{The Gallery of Practical Science}

An advertisement in the Times of January 9, 1835, ran as follows: "Gallery of Practical Science, Adelaide-street and Lowther-arcade, Strand.-The Grand Exhibition is re-opened to the public daily, at 10 o'clock-Steam-engine and carriages travelling on a Rail-road-Clifton Suspension Bridge-Magnets of extraordinary power, producing brilliant light and electric phenomena-Steam Gun discharging 20 balls in a second-Beautiful Illustrations in Optics-Steam Boat Models moving in water-Painting-StatuaryMusic and many entertaining Novelties, including a splendid Microscope. Admission to the whole 1s."

\section{Sir Felix Booth made a Baronet}

On January 10, 1835, the Mechanics' Magazine said : "His Majesty has recently conferred a baronetcy on 'Felix Booth Esq, of Roydon Hall, in the county of Essex', avowedly for his public spirited conduct in fitting out at his own expense the expedition to the Polar regions under the command of Captain Ross. Sir Felix Booth served the office of sheriff of London a fow years ago, but on that occasion escaped the honour of knighthood, so often inflicted on the holders of that dignity, on some such important occasion as the bringing up of a loyal address. It is believed that the present is the first instance of a civic baronetcy having been bestowed for services in the cause of science. Captain Ross has also been knighted and received permission to wear the insignia of his numerous foreign orders in England." Sir Felix Booth was born in 1775 and died in 1850. Boothia Felix was named after him by Capt. Ross.

\section{American Ice sent to India}

In 1834, the American sailing ship Tuscany carried a cargo of ice from North America to India, and on January 10, 1835, the Mechanics' Magazine recorded that the master of the vessel had been presented with a handsome silver vase bearing the inscription : "Presented by Lord William Bentinck, governorgeneral and commander-in-chief of India, to $\mathrm{Mr}$. Rogers, of Boston, in acknowledgement of the spirit and enterprise which projected and successfully executed the first attempt to import a cargo of American ice into Calcutta." About 100 tons of ice was conveyed in the Tuscany. The selling price was $6 \frac{1}{2}$ cents per lb. and it was calculated that "the owners received 12,500 dollars upon an investment which including the cost of all the extra precautions for preserving the ice, did not exceed 500 dollars". 